\title{
Tracing of Sertoli-Cell-Only Syndrome and Other Histopathological Abnormalities in Iraqi Males with Primary Infertility of Azoospermia
}

\author{
Mohemid M. Al-Jebouri' ${ }^{1}$, Salih A. Mdish² \\ ${ }^{1}$ Deapartment of Microbiology, College of Medicine, University of Tikrit, Tikrit, Iraq \\ ${ }^{2}$ Department of Clinical Laboratory, Tikrit Teaching Hospital, Tikrit, Iraq \\ Email: profaljebouri@yahoo.com
}

How to cite this paper: Al-Jebouri, M.M. and Mdish, S.A. (2019) Tracing of Sertoli-Cell-Only Syndrome and Other Histopathological Abnormalities in Iraqi Males with Primary Infertility of Azoospermia. Open Journal of Pathology, 9, 10-17. https://doi.org/10.4236/ojpathology.2019.91002

Received: November 18, 2018

Accepted: January 8, 2019

Published: January 11, 2019

Copyright $\odot 2019$ by authors and Scientific Research Publishing Inc. This work is licensed under the Creative Commons Attribution International License (CC BY 4.0).

http://creativecommons.org/licenses/by/4.0/

\section{cc) (i) Open Access}

\begin{abstract}
Objective: This study aimed to investigate the histopathological examination of the testicular biopsies in infertile males with azoospermia. The patients were referred to the Urology Department in Salah Alden Hospital. Methods: The present study was carried out from May 2017 until June 2018 and the number of the patients group was 60 . The patients aged between 20 to 50 years. 20 of them were selected and subjected to histopathological examinations by taking biopsies from their testes. Results: The sertoli-cell-only syndrome (SCOS) was the most common positive histopathological finding comprising $35 \%$ of the cases. This was followed by testicular atrophy with $30 \%$, while maturation arrest was $20 \%$. The percentage of hypospermatogenesis was $10 \%$ and normal spermatogenesis was 5\%. Conclusion: Among the 20 specimens examined, the sertoli-cell-only syndrome (SCOS) was the most common positive histopathological finding. The semen analysis and testicular biopsy provide valuable information about the etiology and the fertility potential of an individual.
\end{abstract}

\section{Keywords}

Iraqi Male Infertility, Azoospermia, Sertoli Cells, Testicular Biopsy

\section{Introduction}

Infertility is defined as the lack of conception after 12 months of unprotected intercourse. On evaluation, roughly $50 \%$ of affected couples have causal or associated male factors as a cause of infertility [1]. Evaluation of the infertile men requires a complete medical history, physical examination and laboratory inves- 
tigation. Usually, $80 \%$ of couples are able to conceive within the first year of marriage [2]. Male infertility has several different possible causes which are primary or secondary testicular failure, infection and obstruction, but the most common diagnosis is idiopathic infertility, which accounts for about $60 \%-70 \%$ of the patients [3]. Primary infertility is a term used for those couples who have never conceived, while secondary infertility is a term that refers to those couples who have at least one conception but currently unable to achieve pregnancy [4].

Most male factor infertilities are due to testicular failure which results in a decline in semen quality [5]. Most male factor infertilities are represented as a wide range of semen quality from normal spermogram to absence of any sperm in semen. The absence of sperm in semen results from severe failure in testicular function or obstruction of extra-testicular ducts [6]. Azoospermia defined as complete absence of spermatozoa in ejaculate, is present in less than $1 \%$ of men in the normal population, and $10 \%-15 \%$ of infertile men [7]. Azoospermia results from obstruction of extra testicular ducts (obstructive) or testicular dysfunction (non-obstructive) [8].

\section{Materials and Methods}

This study was conducted in Urology Department in Salah Al-Deen Hospital. The number of the patients was 60 and 20 of them were subjected to histopathological examinations who suffered from aspermia. They were recruited from May 2017 until June 2018. The patients aged between 20 to 50 years. Semen and testicular biopsy were collected from infertile man that failure of a couple to become pregnant after one year of regular, unprotected intercourse and submitted for seminal fluid analysis. The present study was conducted in the Department of Pathology. This study was based upon the histopathological examination of the testicular biopsies. The biopsies were obtained from 20 infertile males with abnormal semen examination. The ages of patients were from 20 to 50 years old. Cases for testicular biopsy were selected after taking detailed clinical history, thorough clinical examination and semen analysis. The detailed clinical history including age, the duration of active marriage life, duration of infertility, sexual relationship, frequency of coitus, premature ejaculation, psychological status and libido was noted. Past history of infection like mumps, measles, pneumonia, sexually transmitted diseases (STD), tuberculosis and any surgical procedure was also asked. Secondary sex characters and genital organs examination were done. The inclusion criteria were as follow: Infertile man that failure of a couple to become pregnant after one year of regular, unprotected intercourse. The control group composed of 50 subjects who were looked healthy and had comparable criteria to the patient and composed of 50 males.

Semen analysis was done in all the patients and parameters like total sperm count, motility and presence or absence of abnormal forms were looked into. Before collection, the patients were advised for three days of abstinence. Semen samples were collected in the laboratory room in a clean, dry, biologically inert 
container. In case of oligospermic or azoospermic patients, three semen samples were collected on alternate day and thorough examination was carried out. Spermatozoa were counted using the haemocytometer chamber under high power in all four WBC square using semen diluting fluid consisting of sodium bicarbonate and formalin in distilled water [9] [10] [11] (1:20 dilution). The sperm counting was carried out same as WBC counting. Sperm count is one of the most useful tests for evaluation of fertility in men. As the name implies a semen specimen containing no spermatozoa on at least two examinations was said to be azoospermic. Before stamping azoospermic, the sample must be centrifuged and check the pellet for sperms. The testicular biopsy specimens were taken by urologist after proper cleaning of scrotum with an antiseptic solution, and the area around it is covered with sterile cloth. A local anesthetic was injected into the skin of the scrotum. Then a small incision was made through the skin, and a tiny piece of testicular tissue was removed using "Window's microsurgical technique". 10 Approximately $3 \mathrm{~mm}$ size specimen was excised using "No touch technique" and placed in Bouin's fixative. A single stitch was used to close the incision in the testicle and another stitch is used to close the incision in the skin with an absorbable suture. The scrotal area was then bandaged and patient was informed to wear an athletic support for several days after the procedure. The biopsy took approximately 15 - 20 minutes. Patient had been advised to refrain from sexual activity for 1 to 2 weeks after biopsy and avoid washing the area for several days [12]. After fixation the tissue was processed and paraffin embedded. Sections were cut and stained with haematoxylin and eosin stain. Special staining for elastic fibers, collagen and crystals of reinke were done wherever indicated. In the interpretation of testicular biopsy, attention was paid to the size, shape and population density of seminiferous tubules, the state of basement membrane, various stages of spermatogenesis and components of the interstitial tissue. Since there are no clear guidelines for the range of normality [13].

\section{Statistical Analysis}

The results were expressed mean, standard deviation; statistical analysis of the results was performed using the statistical package software (SPSS), version 15.01 and Excel 2010. Pearsons correlation coefficient was used to determine the relationship between variable for all parameters. The differences were considered significant when $<0.05$.

\section{Result}

Twenty patients of infertile males were selected on the basis of semen examination. Patients with azoospermia, were selected for biopsy. When testes were present in hernial content, the histopathological examination showed various findings like normal spermatogenesis, sertoli cell only syndrome (SCOS) as well as atrophy of testes, maturation arrest and hypospermatogenesis.

Table 1 shows the histopathological examination result that occurs in current 
study. The Sertoli cell only syndrome (SCOS) was the most common positive histopathological finding comprising $35 \%$ of the cases. This was followed by testicular atrophy with $30 \%$, while maturation arrest was $20 \%$. The percentage of hypospermatogenesis was $10 \%$ and normal spermatogenesis was 5\% (Figures $1-8)$.

Table 1. The findings of histopathological examination ofazoospermia males.

\begin{tabular}{ccc}
\hline Histopathological feature & No. & $(\%)$ \\
SCOS & 7 & $35 \%$ \\
Mesticular atrophy & 6 & $30 \%$ \\
Normal spermatogenesis & 4 & $\mathbf{2 0 \%}$ \\
Hypospermatogenesis & 1 & $\mathbf{5 \%}$ \\
Total & 2 & $10 \%$ \\
\hline
\end{tabular}

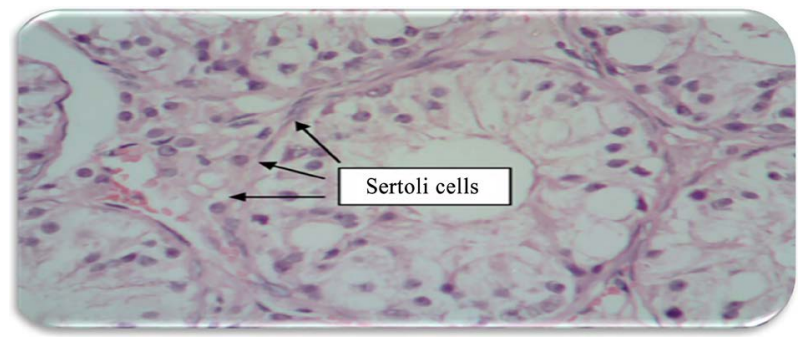

Figure 1. Sertoli cell only syndrome (SCOS).

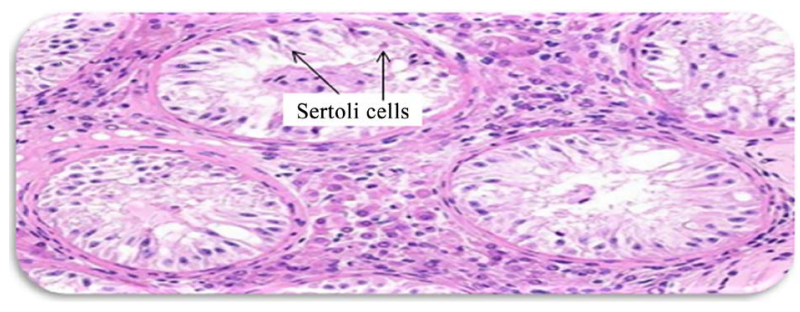

Figure 2. Tubular contain only sertoli cells, and there was a complete absence of germ.

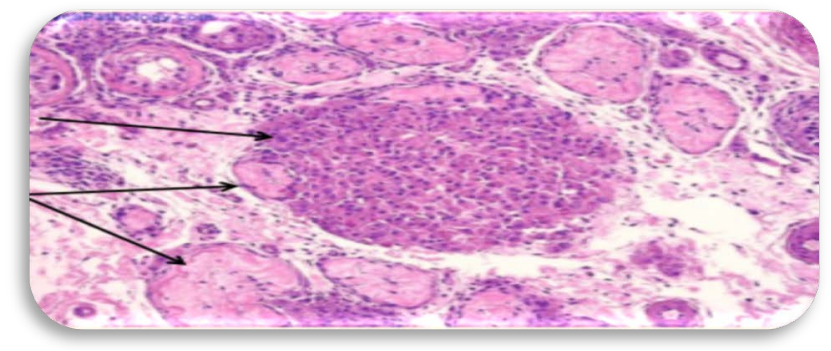

Figure 3. Testicular atrophy, total atrophy of seminiferous epithelium leaving only thickened lamina propria. 


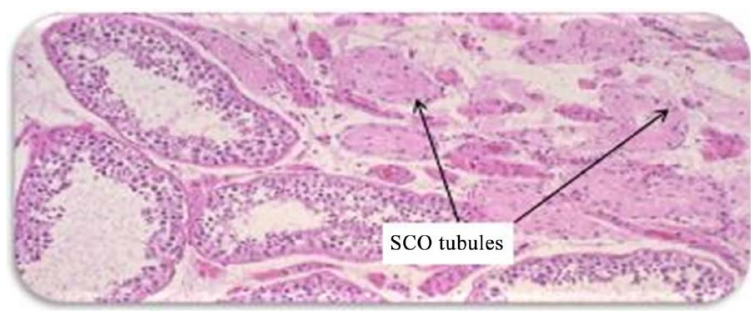

Figure 4. Testicular atrophy may be combined with SCO tubules with or without Leydig cell hyperplasia.

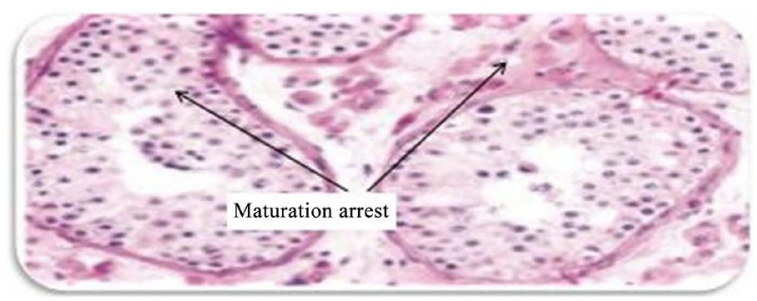

Figure 5. Maturation arrest, many germs cells and spermocytes are seen but no spermatids are seen.

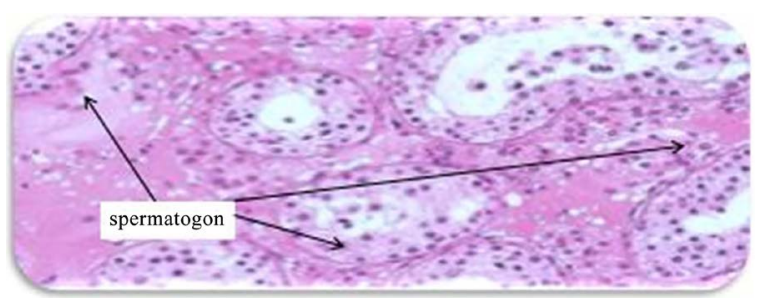

Figure 6. Complete arrest at a particular stage, most often at the spermatogonial or primary spermatocyte stage.

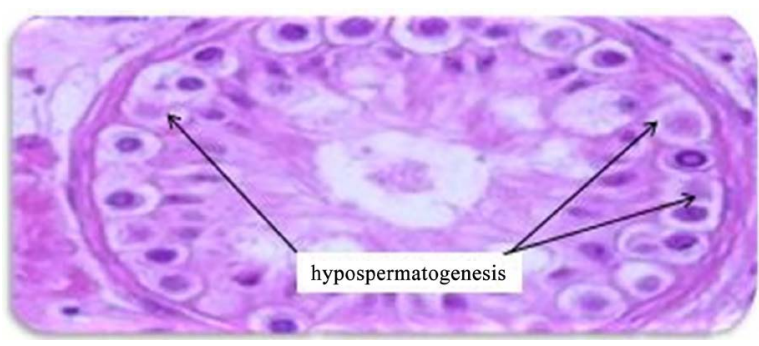

Figure 7. Seminiferous shows the mild tiunca propria thickening and hypospermatogenesis.

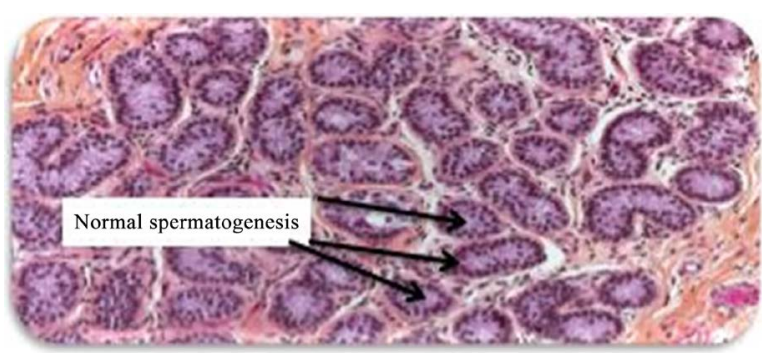

Figure 8. Normal spermatogenesis in the entire biopsy and the presence of normal inter tubular tissue. 


\section{Discussion}

Histological examination of testicular biopsies during the present study revealed that the Azoospermia is the medical condition of a man whose semen contains no sperm. The sertoli cell only syndrome (SCOS) was the most common positive histopathological finding comprising around $35 \%$ of the cases. This finding was followed by testicular atrophy with $30 \%$, while maturation arrest they were formed $20 \%$ of testicular biopsy during the present study, also it was seen hypospermatogenesis with $10 \%$ and normal spermatogenesis with $5 \%$. This result was correlated with Uadia [14] and Emokpae [15]. Similar findings were reported by Trupti et al. [16] and Ahmad et al. [17], found sertoli cell only syndrome (SCOS), testicular atrophy was the major causes of non-obstructive azoospermia followed by maturation arrest. Fertility in these non-obstructive cases is not reversible.

The similar finding was obtained by Kurien et al. [18] who found the patients had normal spermatogenesis when testicular biopsy examination, normal histology suggests either partial or complete obstruction or possibility of anti-sperm antibodies. These findings suggest that the obstructive etiology is one of the other major causes responsible for male infertility and has a good prognosis [16] [19].

This study is corresponds with current European Association of Urology recommendations for the reporting of a testicular biopsy include 1) absence of seminiferous tubules (seminiferous tubule hyalinization), 2) presence of sertoli cells only (sertoli-cell-only syndrome), 3) maturation arrest-incomplete spermatogenesis, not beyond the spermatocyte stage, and 4) hypospermatogenesis-all cell types up to spermatozoa are present, but there is a distinct decline in the number of reproducing spermatogonia. Male sterility without abnormal sexual desire describes a condition of the testes in which only Sertoli cells line the seminiferous tubules. The most likely cause of the syndrome is congenital absence or early neonatal loss of germ cells, but it may also be secondary to genetic defects or androgen resistance. In hypospermatogenesis a represents intact tubules, the overall feature of hypospermatogenesis is a reduced number of germ cells, resulting in a decreased number of intact tubules'overall feature of hypospermatogenesis is a reduced number of germ cells, resulting in a decreased number of intact tubules. The overall feature of hypospermatogenesis is a reduced number of germ cells, resulting in a decreased number of intact tubules [21]. The degree of hypospermatogenesis can be mild, moderate, or severe. While maturation arrest refers to failure of germ-cell development at any prefinal stage. True maturation arrest affects all tubules and typically occurs monomorphically at the spermatocyte stage [22].

In testicular atrophy is a medical condition in which the male reproductive organs (the testes, which in humans are located in the scrotum) diminish in size and may be accompanied by loss of function. This does not refer to temporary changes, such as those brought on by cold. Testicular atrophy may be associated with several causes, such as hormonal problems, intake of medications or diseases such as varicocele [23]. 
The main causes of these conditions are not known, but the rapid pace of increasing incidence of azoospermia and other conditions responsible for male factor infertility point to environmental factors. Chromosomal abnormalities have also been reported to be as one of the genetic factors contributing to male infertility [24]. Endocrine disrupting chemicals and genetic polymorphisms have been hypothesized to influence male reproductive health [25].

\section{Ethical Approval}

Ethical clearance for the study was obtained from the Committee of Higher Studies in College of Medicine, University of Tikrit. The researcher did not in any way expose participants of the study to physical or psychological harm. Participation in the study was strictly voluntary with the informed consent of participants that guaranteed their right to privacy. All authors hereby declare that all experiments have been examined and approved by the appropriate ethics committee and have therefore been performed in accordance with the ethical standards laid down in the 1964 declaration of Helsinki.

\section{Conclusion}

Semen analysis and testicular biopsy provide valuable information about the etiology and the fertility potential of an individual. The suspected infertile males reported here were mostly suffered from Sorteli-Cell-Only syndrome.

\section{Conflicts of Interest}

The authors declare no conflicts of interest regarding the publication of this paper.

\section{References}

[1] Jacobson, M.H., Chin, H.B., Mertens, A.C., Spencer, J.B., Fothergill, A. and Howards, P.P. (2017) Research on Infertility: Definition Makes a Difference. American Journal of Epidemiology, 187, 337-346. https://doi.org/10.1093/aje/kwx240

[2] Jarow, J.P., Sharlip, I.D., Belker, A.M., Lipshultz, L.I., Sigman, M., Thomas, A.J., Schlegel, P.N., Howards, S.S., Nehra, A., Damewood, M.D. and Overstreet, J.W. (2002) Best Practice Policies for Male Infertility. The Journal of Urology, 167, 2138-2144. https://doi.org/10.1016/S0022-5347(05)65109-9

[3] Jarow, J.P., Coburn, M. and Sigman, M. (1996) Incidence of Varicoceles in Men with Primary and Secondary Infertility. Urology, 47, 73-76. https://doi.org/10.1016/S0090-4295(99)80385-9

[4] Al-Jebouri, M.M. (2015) A Regional Study on the Infertility of Iraqi Males under War Impact from 1980 to 2013. World Journal of Pharmaceutical Research, 4, 497-503.

[5] Sobek, A., Hrbková, K., Mucha, Z., Vodicka, J., Tesarová, M., Zátura, F., et al. (1998) Infertility Treatment of Men with Non-Obstructive Azoospermia. Acta Universitatis Palackianae Olomucensis Facultatis Medicae, 141, 83-85.

[6] Song, G.J., Lee, H., Park, Y., Lee, H.J., Lee, Y.S., Seo, J.T., et al. (2000) Expression Pattern of Germ Cell-Specific Genes in the Testis of Patients with Nonobstructi- 
veazoospermia: Usefulness as a Molecular Marker to Predict the Presence of Testicular Sperm. Fertility and Sterility, 73, 1104-1108.

https://doi.org/10.1016/S0015-0282(00)00520-3

[7] Jarow, J.P., Espeland, M.A. and Lipshultz, L.I. (1989) Evaluation of the Azoospermic Patient. The Journal of Urology, 142, 62-65.

https://doi.org/10.1016/S0022-5347(17)38662-7

[8] Anguiano, A., Oates, R.D., Amos, J.A., Dean, M., Gerrard, B., Stewart, C., et al. (1992) Congenital Bilateral Absence of the Vas Deferens. A Primarily Genital Form of Cystic Fibrosis. Journal of American Medicine Administration, 267, 1794-1797.

[9] Sarkar, S. and Henry, J.B. (1996) Andrology Laboratory and Fertility Assessment. Clinical Diagnosis and Management by Clinical Methods. 19th Edition, 507-514.

[10] World Health Organization. (1987) Laboratory Manual for the Examination of Human Semen. 2nd Edition.

[11] Cheesbrough, M. (2006) Examination of Semen. In: District Laboratory Practice in Tropical Countries, Part II, 2nd Edition, Replika Press Pvt. Ltd., India, 130-132.

[12] Goldstein, M. (2002) Testicular Biopsy. In: Walsh, R. and Wein, V., Eds., Campbelf $s$ Urology, 8th Edition, W.B. Saunders and Company, 1534-1537.

[13] Wong, T.W., Straus, F.H. and Warner, N.E. (1973) Testicular Biopsy in Study of Male Infertility. Obstetrical \& Gynecological Survey, 95, 151-159. https://doi.org/10.1097/00006254-197309000-00020

[14] Emokpae, M.A., Uadia, P.O., Mohammed, A.Z. and Omale-Itodo, A. (2006) Hormonal Abnormalities in Azoospermic Men in Kano, Northern Nigeria. Indian Journal Medicine Research, 124, 299-304.

[15] Emokpae, M.A. (1999) A Review of Laboratory Investigations of Male Infertility. The Nigerian Journal of Medicine, 8, 104-107.

[16] Purohit, T.M., Purohit, M.B. and Dabhi, B.J. (2004) Study of Semen Analysis and Testicular Biopsy in Infertile Male. Indian Journal Pathology Microbiology, 47, 486-490.

[17] Ahmad, M., Ahmad, M., Ahmad, R. and Khan, N. (2002) Role of Testicular Biopsy in Male Infertility. Pakistan Armed Forces Medicine Journal, 52, 66-71.

[18] Kurien, A., Mammen, K. and Jacob, S. (2003) Role of Fine Needle Aspiration Cytology of Testes in Male Infertility. Indian Journal Urology, 19, 140-144.

[19] David, N.R. (1993) Clinical Evaluation of Infertile Couple. In: Ivan, D., Pathology of Infertility, Mosby, 37-43.

[20] McClure, R.D. (1987) Endocrine Investigation and Therapy. Urology Clinical North American, 14, 471-488.

[21] Bermann, M. and Kliesch, S. (1998) Hodenbiospie. In: Krause, W. and Weidner, W., Eds., Andrologie, VerlagStuttgart, Stuttgart, 47-55.

[22] Tesarik, J., Bahceci, M., Ozcan, C., Greco, E. and Mednoza, C. (1999) Restoration of Fertility by In-Vitro Spermatogenesis. The Lancet, 353, 555-556. https://doi.org/10.1016/S0140-6736(98)04784-9

[23] Fitzgibbons, R.J., Greenburg, A.G. and Nyhus, L.M. (2002) Nyhus and Condon's Hernia. Lippincott Williams and Wilkins, Philadelphia, 294.

[24] Nagvenkar, P., Desai, K., Hinduja, I. and Zaveri, K. (2005) Chromosomal Studies in Infertile Men with Oligozoospermia and Non-Obstructive Azoospermia. Indian Journal Medicine Research, 122, 11-12.

[25] Weber, R.F. and de baat, C. (2000) Male Fertility. Possibly Affected by Occupational Exposure to Mercury. Nederlands Tijdschr Tandheelkd, 107, 495-498. 